\title{
Comportamento da raça Light Sussex em Piracicaba
}

\author{
PROF. A. DI PARAVICINI TORRES \\ Escola Superior de Agricultura "Luiz de Queiroz" \\ Universidade de Săo Paulo
}

\begin{tabular}{|c|c|c|}
\hline \multicolumn{3}{|c|}{ INDICE } \\
\hline Introduçâo $\ldots .$. & Conclusōes & 407 \\
\hline$O$ que se diz da Light Sussex 40 & Resumo & . 408 \\
\hline que observamos na Light & Abstract & 408 \\
\hline Sussex. & Bibliografia & 408 \\
\hline
\end{tabular}

* Trabalho da Seçăo de Avicultura e Cunicultura. 


\section{INTRODUÇAOO}

Há três anos, por ocasião da organização da Seção Técnica de Avicultura da E. S. A. "Luiz de Queiroz", fazia-se grande propaganda neste país em tôrno da raça de galinhas de dupla utilidade "Light Sussex", que até então, nenhuma repercussão tivera.

Tendo necessidade de uma raça de seu tipo para cruzamentos e comparações com Rhode I. Red, adquirimos 500 pintos da Granja Sagrado Coração, no Rio de Janeiro, dos quais criámos pouco mais de 300. Estas aves foram reproduzidas em 1945 e 1946, de forma que se controlaram três geraçōes : a dos pintos adquiridos, filhas e netas, cuja postura está encerrandose no corrente ano.

Constando de nosso programa de trabalho observaçóes: sóbre o comportamento desta raça afim de ser recomendada ou não para nosso meio, damos à publicidade estas notas, em virtude de não pretendermos continuar com o referido trabalho, que damos por encerrado.

\section{O QUE SE DIZ DA LIGHT SUSSEX}

A descrição da raça Light Sussex é omitida porque se encontra nos "Standards de Perfeição Avícola" inglês, americano, argentino e numerosos livros de avicultura.

Embora criada desde séculos nos condados de Surrey, Kent e Sussex, para abastecimento do mercado de Londres de "chickens" ou "table fowls", só foi reconhecida como raça a partir de 1903. Desde aqueles tempos era considerada uma raça produtora de carne muito fina, branca, tenra e suculenta, com ossatura fina e uma abundancia de carne, que determinava um elevado rendimento.

Existem de fato quatro variedades da raça : a "Red" vermelha, a "Speckled" pintada, a "Brown" parda e a "Light" clara ou arminhada, que é objeto dêste estudo. Esta última é a preferida pelos criadores por ter melhor postura, notadamente no inverno, dar pintos mais rústicos, embora tenha ovos um pouco menores que os das demais variedades.

Diz-se que há casos de frangas que começam a pôr com 4 meses, no que acreditamos, pois são realmente muito preco- 
ces. Dão ovos grandes (50-70) e coloridos. Chocam precocemente também e são excelentes mães. Com facilidade se adaptam em qualquer lugar, suportando bem o frio. Os pintos são robustos, faceis de criar, crescem ràpidamente e os frangos engordam com facllidade.

O maior contingente de frangos para o mercado de Londres provém desta raça. Geralmente é criada por pequenos proprietários ("Cottagers") que vendem sua produção diretamente ou a engordadores que utilizam grandes "hangars" onde realizam a engorda forçada em 2 ou 3 semanas, sobretudo com farinha de aveia.

O principal característico da raça é o comprimento do dorso e das espáduas e sua forma chata que aparenta o dorso mais curto do que realmente é.

\section{O QUE OBSERVAMOS NA LIGHT SUSSEX}

As observações que publicamos referem-se a uma população da raça, mistura de linhagens aparentadas, gozando de certà uniformidade, que de forma alguma servem para comparar com qualquer rebanho da mesma raça. Não obstante, não só confirmam o que se diz da raça, como estáo de acôrdo com o ponto de vista de outros criadores neste país.

Ovos - Os ovos são grandes, rosados, claros, em geral bem conformados. Mesmo nas frangas de primeira postura o volume do óvo cresce ràpidamente e atinge um alto péso comparativamente à maioria das raças. $O$ pesso médio foi em outubro de 1945 de 58,8 grs. para aves de um ano de idade, pêso êste notadamente superior ao dos ovos de nossas Rhode I. Red.

Pintos - Os pintos são grandes, volumosos em correspondéncia com o péso do ôvo, muito emplumados, fortes, não muito vivos, bons comedores e crescem ràpidamente. Em vários contrastes efetuados com $R$. I. Red sobrepujou-os na rapidês do crescimento.

Franguinhos - São muito precoces e resistentes e criamse tão bem no sistema de criação racional do aviárío como no sistema "caipira". Nessa idade distinguem-se dois tipos de frangas muito diferentes e que mais tarde se uniformizam: (a) um típo delgado e rabudo (aproximando-se do tipo Mediterráneo) e (b) outro mais compacto, pesado, com pouca cauda c de desenvolvimento muito maior (tipo Asiático). Uma seleção poderia ser realizada para eliminar um dos tipos, o que não 
foi tentado. Como ocorre na maioria das raças mistas, a distínção precoce do sexo pelo dimorfismo năo é muito fácil.

Frangas - São muito precoces, começando a postura com 5 meses, em média de 15 dias mais cêdo que a $R$. I. Red. Entre os 6 e 7 meses a maioria das frangas está botando, sendo pequeno $o$ número de aves que retarda a postura.

Aos 12 meses as frangas pesam em média 2500 grs., isto é, 220 grs. (menos de 10\%) abaixo do "standard", enquanto na mesma época o péso dos frangos escolhidos para a reprodução acusou uma média de 3420 grs., isto é, 20 grs. acima do exigido pelo padrão da raça. Entretanto não havia sido feita nenhuma seleção das frangas pelo pêso, mas simplesmente pela precocidade, postura, saúde, etc. possivel que a seleçáo pela precocidade de postura tenha afetado o péso do lote, porque em geral as frangas mais tardias atingem pesos mais elevados.

Frangos - O péso dos frangos segundo estimativas reali7.adas por BERGAMIN e JARDIM, num trabalho publicado nestes Anais foi aos 4 meses de 1650 grs., aos 5, de 2170 e 2470 aos 6 , porém êsses frangos foram em parte prejudicados no seu desenvolvimento devido às condiçóes da experiencia, em parque bastante restrito, permitindo supor-se que pesos malores podem ser conseguidos com facilidade.

Postura - O característico mais importante da postura de nosso rebanho é a intensidade grande, isto é, a faculdade de produzir muitos ovos em dias consecutivos, sem interrupçăo ("clutch"). A persistência também é boa, embora às vezes interrompida por uma ou duas paradas de um mes mais ou menos.

Durante i postura, em quasi tódas as aves controladas observaram-se frequentes interrupçós, em parte atribuida ao checco, em parte à pausa invernal - uma parada num dos meses de inverno. Já temos criado várias raças de galinhas e nunca observamos pausa invernal, provàvelmente devido à benignidade de nosso clima. possivel que se trate de uma falta de aclimação, pois o rebanho originou-se de aves de importação recente, ou então não sofreram ainda uma seleção adequada dentro dêste novo ambiente.

Chôco - O chóco ocorre uma ou mais vezes, prejudicando a postura. T'nhamas, a princípio, esperança de encontrar algumas galinhas isentas dêste atributo, o que não ocorreu, mesmo no nosso segundo ano de trabalho quando criámos cerca de 600 frangas. Quando não chocam no $10^{\circ}$ ano, chocam o 
seguinte e assim ficámos acreditando na pouca probabilidade de eliminar este atributo hereditário que parece encontrar-se em estado de homozigose.

Fertilidade - Antes de iniciarmos nossa criação, ouvimos dizer que a Light Sussex tinha baixa fertilidade. De fato pudemos observar uma frequência maior de galos inferteis ou pouco férteis nesta raça do que na R. I. Red., de nosso rebanho, mas como sempre que um galo mostrava-se pouco fertil era substituido e como usávamos sempre galos jovens, conseguimos manter uma fertilidade boa ou normal (85\%), năo obstante inferior à da nossa R. I. R., cuja fertilidade sempre foi otima (95\%). De forma que enquanto se obtinham 85 pintos de R. I. R. para 100 ovos deitados, conseguíamos para o mesmo número de ovos de Sussex apenas 75 pintas.

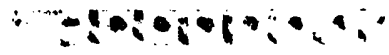

\section{CONCLUSOES}

Pelas caracteristicas apresentadas pela Light Susssex, tanto pelo que se diz como pelo que observámos, chegámos à conclusão de que esta raça possue excelentes qualidades que a tornam indicada para a criação doméstica, isto é, criaçóes pouco numerosas onde as próprias galinhas săo empregadas na incubação dos ovos. Adaptou-se perfeitamente às nossas condiçóes e seria uma das raças indicadas para substituir a galinha caipira nos sitios, como produtora tanto de frangos grandes de carne excelente como de ovos graúdos e abundantes; provàvelmente produzirá o dóbro das caipiras, cuja produçáo se estima em 70 a 80 ovos por ano em média.

O chóco, entretanto, que é nas aves de criação doméstica uma excelente qualidade constitue um grave defeito para as aves de criação industrial, por cujo motivo consideramos condenável recomendar esta raça para granjas de um ou alguns milhares de cabeças.

As granjas que desejarem trabalhar com Light Sussex deverão limitar-se a criá-las afím de venderem ovos de reprodução ou pintos para os pequenos criadores (sitiantes), c que aliás constitue um bom negócio, havendo uma procura não muito pequena de pintos desta raça. Como galinha de granja de tipo misto, náo pode entretanto competir com a R. I. R.. :uja tendencia ao choco é muito menos acentuada e que produz, em média, maior quantidade de ovas.

Em relação à qualidade da carne, devido provàvelmente à 
falta de hábito em comer carne branca, temos notado uma p:eferência do público em Piracicaba pela carne da Rhode. mais sêca e amarela e menos tenra. A carne da Light Sussex cozinha muito mais ràpidamente que a da Rhode, desprendendo com facilidade dos cssos, num tempo de cocção normal.

\section{RESUMO}

Na Seção Técnica de Avicultura e Cunicultura desta Escola foram feitas durante três anos observaçð̄es sóbre 0 comportamento da raça Light Sussex, em contraste sobretudo com a Rhode I. Red. Verificou-se ser mais precoce no desenvolvimento, mais pesada, de carne mais tenra, de maior intensidade e menor persistência de postura, de menor fertilidade, de maior precocidade de postura, de maior predisposição ao chôce e de maiores ovos.

Apresenta boas qualidades de adaptação e criação que a toinam muito recomendável para as pequenas criaçóes case:ras ou dos sitios, no mesmo sistema em que é geralmente criada na Inglaterra.

Só excepcionalmente convirá a uma granja industrial preocupar-se com sua criação em larga escala.

\section{ABSTRACT}

Three years of observations on Light Sussex breed conducted at the Poultry Departament of "Luiz de Queiroz" School of Acr:culture are reported in this paper. The breed was compared mainly with the Rhode Island Red and the following conclusion obtained : The Light Sussex is fast growing, early maturing heavier, fine fleshed, more persistent and with greater clintchs. greater groodiness and lays larger eggs.

The breed shows quality of adaptation being recommented for town or farm flocks in the same way generally used in England: Exceptionally could be recommended for commercia! flocks.

\section{BIBLIOGRAFIA}

DÜRINGEN, B., 1931 - Tratado de Avicultura, vers. 5.a ed. alemã por E. M. M. Amador, Barcelona. 
BLANCHON, H. L. ALPH e DE MONCHAUX, D., 1924 - Toutes les Poules et leurs Varietés, Paris..

TORRES, A. DI P., 1946 - A raspa da mandioca na alimentação das galinhas, in Anais da E. S. A. L. Q. vol. 3, pp. 329-338.

TORRES, A. DI P. e BERGAMIN, A., 1946 - A couve flor na alimentação da galinha, in Anais da E. S. A. L. Q., vol. 3, pp. 388-398.

BERGAMIN, A., 1946 - A ração úmida no crescimento dos pintos, in Anais da E. S. A. L. Q., vol 3, pp. 437-446.

BERGAMIN, A, e JARDIM, W. R., 1947 - Comparação da Raça R. I. Red, Light Sussex e seu Mestiço - Ovos, pintos e frangos, in Anais da E. S. A. L. Q., vol. 4.

1928 - Standard Argentino de Perfeccion Avicola, 2.a ed. Associação Argentina "Criadores de Aves, Conejos y Abejas". 